\title{
Cushing syndrome
}

INSERM

\section{Source}

INSERM. (1999). Orphanet: an online rare disease and orphan drug data base. Cushing syndrome. ORPHA:553

Cushing's syndrome (CS) encompasses a group of hormonal disorders caused by prolonged and high exposure levels to glucocorticoids that can be of either endogenous (adrenal cortex production) or exogenous (iatrogenic) origin. 